\title{
MONUMENTE TER GEDAGTENIS AAN LT. KOL HENNING P.N. PRETORIUS (1844-1897) IN DIE TRANSVAALSE HOOFSTAD
}

\author{
Kol Dr Jan Ploeger*
}

\section{Die Agtergrond}

Die korps 'Staatsartillerie van die Z.A. Republiek' se benaming is aan Wet No. 1 van 1896 ontleen en het vanaf sy ontstaan in 1881 ' $n$ verwarrende geskiedenis belewe. Sowel F.J. du Toit Spies, in Pretoria 1855-1955 (Pretoria, 1955) as G.N. van den Bergh in sy proefskrif Die Polisiediens in die Zuid-Afrikaansche Republiek (Argiefjaarboek vir Suid-Afrikaanse Geskiedenis, 1975) het oortuigende bewyse gelewer om hierdie uitspraak te staaf.

Ofskoon, aldus laasgenoemde skrywe, genl P.J. Joubert meermale bely het dat hy nie oor aanleg vir militêre organisasie beskik het nie, is hy na die Eerste Anglo-Boereoorlog (1880-1881) met die organisasie van die militêre en plattelandse polisie-organisasie belas. Noodgedwonge het hy sy toevlug geneem tot art. 19 van die Transvaalse grondwet van 1877 en die daaropvolgende Britse militêre- en polisiebeplanning van die anneksasietydperk. Só kon dit dan gebeur dat, in die voormalige Britse militêre kamp aan Potgieterstraat, Pretoria, later bekend as die Artilleriekamp, in 1881 'n artilleriekorps onder kapt $J$. Pelser sowel as 'n polisiekorps onder kapt lan Ferreira gehuisves is. Genl Joubert moes aanskou dat kapt Ferreira se korps 'n volslae mislukking was, terwyl hy kapt Pelser ontslaan het.

In 1882 is die twee korpse, ten spyte van hulle uiteenlopende organisasies en doelstellings, onder die benaming 'Transvaalsche Artillerie Corps', met kmat N.P.N. Pretorius, 'n vroeëre veldkornet van Lydenburg verenig kragtens Wet No. 8 van 1882. Vier jaar later moes dié benaming plek maak vir dié van 'Rÿdende Staatsartillerie en Politie Corps.' Wat die werksaamhede van dié korps betref, is veral nadruk op polisiepligte gelê, terwyl kmdt Pretorius op die uitvoering van suiwer militêre pligte deur die korpslede aangedring het.

In 1891 is ' $n$ hoofkommissaris van Polisie aangestel, maar deurdat hierdie amptenaar sy op- dragte van genl. Joubert ontvang het, is ' $\mathrm{n}$ volslae skeiding van die gesagstruktuur nie verwesenlik nie. Eindelik, met die aanname van Wet No 11 van 1895, bekend as die Polisiewet, waardeur die polisie en die speurpolisie van die Republiek, onder ' $n$ hoofkommissaris, onder die staatsprokureur se gesag geplaas is, kon sowel die artillerie as die polisie 'n tydperk van funksioneel gesonde ontwikkeling tegemoet gaan.

Daar was meer remmende faktore, behalwe die wat reeds genoem is. Volksraadslede het gedink dat ' $n$ artilleriekorps oorbodig was en steeds minder geld vir die instandhouding van die korps beskikbaar gestel. Die opleiding en dissipline het te wense oorgelaat, die geboue was te klein en vervalle, die geskut was verouder en die ammunisievoorraad dikwels ontoereikend. In 1893 het ' $n$ kommissie gekla oor algemene wanbestuur en bestaande wantoestande. Hierdie klagtes het daartoe gelei dat administrateur kapt A. Abori sy bedanking ingedien het.

Temidde van hierdie tekortkomings en rampe was daar ewewel 'n paar ligpuntjies, t.w. die oprigting van 'n artillerie-musiekkorps onder kapelmeester It J. Maggs en die daarstelling van die veldtelegrafie-afdeling onder It P.C. Paff (1890). In dieselfde lig moet ook die besluit gesien word om 'n tweetal jong offisiere die latere It P.E. Erasmus en It Jan Francois Wolmarans, 'n seun van die vroeëre Uitvoerende Raadslid J.M.A. Wolmarans, vir militêre opleiding na die 'Koninklÿke Militaire Academie' te Breda, Nederland, te stuur.

Die Jamesoninval het die Zuid-Afrikaansche Republiek, wat sy onafhanklike voortbestaan en sy verdedigingstelsel en die doeltreffendheid daarvan betref, tot op sy fondamente laat skud.

Dié gebeurtenis was die begin van die einde van die gesketste, dikwels koerslose beleid ten opsigte van verdedigingsaangeleenthede. Die re- 
gering het wakker geskrik en, in die vorm van 'n reeks deurtastende maatreëls, die militêre organisasie en die weerbaarheid van die artilleriekorps, die polisie en die dienspligtige burgers inderhaas en teen groot koste begin opknap. Binne die bestek van hierdie bydrae noem ons hier slegs Wet No. 1 van 1896, bekend as die 'Wet voor die Staats-Artillerie van die Z.A. Republiek wat vir die eerste maal in die Staatscourant' van 17.6.1896 gepubliseer en 'n maand later in werking getree het.

\section{Kmdt (later: It-kol) Henning Petrus Nicolaas Pretorius}

Henning Petrus Nicolaas Pretorius (Pietermaritzburg, 9.2.1844 - Abrahamschool, distrik Albany, 25.1.1897), wie se grootvader 'n broer van genl Andries W.J. Pretorius en sy moeder 'n dogter van die Voortrekkerleier Piet Retief was, het sy militêre loopbaan tydens die Sekhukhune-oorlog (1876) as 'n veldkornet (distrik Middelburg) begin. In 1883 het hy aan die militêre ekspedisie teen Niabel deelgeneem om, in 1894, 'n leidende rol in die stryd teen Maleboch te speel. Tydens die anneksasie van Transvaal het hy hom op 16.1.1881 tydens 'n skermutseling tussen 'n Britse kolonne en 'n aantal burgers te Elandsfontein, naby Pretoria, onderskei. In die verwerking van eerw Christoph Sonntag se dagboek My Friend Maloboch, Chief of the Blue Mountains (Pretoria, 1983) tree kmdt Pretorius, wat deur die sendeling as 'elderly, with a gruff but decent disposition' (p. 52) beskryf is, hier en daar op die voorgrond. Navorsers het verder, tot vandag toe, onvoldoende tyd en aandag aan die eerste bevelvoerder van die Staatsartillerie gewy, sodat ons nie weet nie hoe hy - onder al die organisatoriese veranderings en tydelike insinkings wat sy korps getref het, gereageer het. Op 15.2.1896 is hy tot die rang van luitenantkolonel bevorder en tydens sy verlof het die dood hom weggeruk aan die begin van 1897. Sy opvolger, It-kol Stephanus Petrus Erasmus Trichardt (Ohrigstad, 23.1.1849 - Nkuru, Kenia, Oktober 1907), sou getuie en deelgenoot in die reorganisasie- en uitbreidingsbeleid ten opsigte van die Staatsartillerie wees en later, met 'n keurkorps, die oorlog van 1899-1902 tegemoet tree.

\section{Die monumentekommissies werksaamhede}

In die Transvaalse Argiefbewaarplek, Uniegebou, Pretoria is daar, onder die KG-groep 'n aantal gegewens met betrekking tot die strewe wat aan die dag gelê is om die gedagtenis van die heengegane militêre bevelvoerder in die vorm van 'n tweetal monumente te eer. Die een monument sou op die laaste rusplek van die oorledene, in die ou begraafplaas, KerkstraatWes, Pretoria, verrys terwyl die ander vorm van 'n gedenknaald sou aanneem wat voor die hoofgebou van die Artilleriekaserne (nou: Verdedigingshoofkwartier), Potgieterstraat, Pretoria sou verrys.

In verband met die eersgenoemde monument, 'n staande grafsteen, is min bekend, behalwe dat fondse vir dié doel deur lede van die korps ingesamel is.

Met betrekking tot die gedenkteken is daar, vermoedelik aan die begin van Februarie 1897, 'n byeenkoms van vriende en belangstellendes te Pretoria gehou met die doel om te bespreek wat gedoen word om die gedagtenis aan die oorledene op 'n gepaste wyse te eer.

Die inisiatief vir die byeenkoms het van die vroeëre sekretaris van die Departement van die Kommandant-generaal F.C. Stiemens, en eerste klerk P.J. Loots uitgegaan. Aanwesig was spoorwegkommissaris W.C. Meyer, F.C. Stiemens, It Thomas Kroon (Staatsartillerie), klerk J.P.J. Botha (Departement van die KommandantGeneraal), maj P.E. Erasumus (Staatsartillerie), sekretaris L.F. de Souza (Departement van die Kommandant-Generaal), dr T.L. Laxton (Staatsartillerie), G.E.J. Bohlmann, P. Zeederberg, It P.C. Paff (Staatsartillerie, Departement van die Kommandant-Generaal), die reedsgenoemde P.J. Loots en H. Groenewald (Staatsartillerie, wapensmid). Tydens hierdie byeenkoms is J.S. Smit eenparig as voorsitter benoem, terwyl maj Erasmus die volgende, voorlopige komitee voorgestel het, wat uit die volgende lede sou bestaan: J.P.J. Botha, It J. Kroon, G.F.J. Bohlmann, P. Zeederberg, maj P.E. Erasmus, W.C. Meyer, It P.C. Paff, 21t M.J. de Jager (Staatsartillerie), dr T.L. Laxton, F.C. Stiemans, P.J. Loots en kapelmeester It J. Maggs. Uit die notule van hierdie byeenkoms is dit nie duidelik of hierdie voorstel bespreek is nie. Van J.P.J. Botha was die voorstel afkomstig om 'n gedenkteken op te rig en dat dadelik begin moes word om fondse in te samel.

Op 4.2.1897 het, onder voorsitterskap van J.S. Smit, die vraag aandag geniet waar die gedenkteken opgerig sou word. Maj Erasmus het die Artilleriekamp voorgestel en daaraan toegevoeg 'voor welke Corps de Commdt zovele diensten heeft gedaan.' Verder is duidelik gemaak dat die 
oprigting van die gedenkteken niks te doen sou hê met die 'grafsteen of graftombe' nie waaromtrent deur offisiere van die Staatsartillerie met die regering onderhandel sou word.

Daar is besluit om ' $n$ kommissie van vier lede, uit die geledere te benoem om die regering te nader of ' $n$ terrein vir die gedenkteken in die Artilleriekamp afgestaan kon word. Terselfdertyd kon die regering dan oor die kommissie se doelstellings ingelig word. Die aanvraag vir die terrein moes aan genl Joubert gerig word en nadat die regering se goedkeuring verkry was, kon 'n vergadering belê word om pryse en 'n tekening van die monument te bekom. Daarna sou, tydens ' $n$ openbare vergadering, die publiek ingelig, die planne voorgelê en met die uitstuur van intekenlyste begin word. ' $n$ Staande kommissie sou vervolgens met die uitvoering van die planne belas word.

Die eerste stap was dat J.S. Smit, maj P.E. Erasmus, F.C. Stiemens en J.P.J. Botha hulle opwagting by die Uitvoerende Raad sou maak.

Op 9.2.1897 is besluit om posmeester-generaal J.N. van Alphen aan die afvaardiging toe te voeg, terwyl op 10.2.1897 die afvaardiging genl Joubert sou versoek om sy medewerking met betrekking tot die benodigde terrein te verkry, om as erevoorsitter van die breëkommissie op te tree en om die afvaardiging na die Uitvoerende Raad te vergesel.

Die Uitvoerende Raad was bereid om die planne te ondersteun. Toestemming in verband met die terrein sou verkry word en op 10.2.1897 is besluit om intekenlyste, soos bewoord deur Stiemens en Loots, te laat druk en aan landdroste te stuur wat dan as erelede van die kommissie sou optree.

Vyf dae later is besluit om, met die oog op die insameling van fondse, Pretoria in ' $n$ viertal wyke te verdeel. Dr Laxton, maj Erasmus, P Zeederberg en G.F.L. Bohlmann sou, in dié wyke, beheer uitoefen, terwyl Stiemens, It Kroon en Van Alphen geld by hoofamptenare sou kollekteer. Botha sou die Volksraadslede nader, advertensies sou in koerante geplaas word, terwyl Loots, as sekretaris-tesourier, sou sorg dat die fonse by die 'Nationale Bank', Pretoria, gedeponeer sou word.

Op die gedrukte lyste is die volgende kommissielede vermeld: Genl P.J. Joubert (ere-voorsit- ter), J.S. Smit (Voorsitter), lede: J.N. van Alphen, W. Meyer, F.C. Stiemens, maj P.E. Erasmus, It T. Kroon, J.P.J. Botha, L.F. de Souza, dr T.L. Laxton, G.F.J. Bohlmann, P. Zeederberg, It P.C. Paff, K.R. Keizer, H. Groenewald, en P.J. Loots (sekretaris).

\section{Die intekenlyste}

Die intekenlyste vermeld o.m. die volgende skenkers en skenkings:

Staatspresident S.J.P. Kruger - £3, genl P.A. Cronjé - $£ 2$, Uitvoerende Raadslid en notulehouer J.H.M. Kock - £2. Uitvoerende Raadslid J.M.A. Wolmarans - £2:2:0. Uitvoerende Raadslid S.W. Burger - £1:1:0, Staatsekretaris dr W.J. Leyds $£ 1: 1: 0$, S. Wierda (Departementshoof van Openbare Werke) - £10:0:0, dr Laxton - £5, It J.M. Wolmarans - £10, It M.J. de Jager - £3:3:0, It P.C. Paff $-£ 5$, It T. Kroon £5, genl P.J. Joubert - £15, dr N. Mansvelt (Departement van Onderwys) $-£ 1$ en vk Melt Marais $£ 10$.

Ook is die volgende bydraes ontvang: Die firma Le Greusot (Schneider en Kie) - £10, L. Grunberg en S. Leon - £10, die firma Friedrich Krupp (Grusonwerk) - £25, H.C. Werner en O. von Deurtz - £25, stadsingenieur E. Lutz (Pretoria) $£ 10$, die firma T. Beckett en Kie (Pretoria) £50. Zeederberg het, in sy wyk, £59 ingesamel, terwyl die Johannesburgse mynmagnaat $H$. Eckstein $£ 10: 10$ : ten bate van die kinders van die oorledene bygedra het.

Die landdroste van Lydenberg, Waterberg en Wakkerstroom het onderskeidelik elkeen ruim $£ 2$, £42 en £36 gestuur. Van hulle kollegas te Rustenburg en Ermelo is ruim £2 en ruim £4 ontvang. Die noodlottige gevolge van die runderpers het die bevolking in sommige distrikte in so ' $n$ mate verarm dat die landdros van Waterberg byna nie die moed gehad het nie om die burgers te vra om iets by te dra. Van Rustenburg is ' $n$ soortgelyke mededeling van die veldkornet te Vlaklaagte ontvang, terwyl die landdros te Lichtenburg - vermoedelik vir dieselfde rede nie meer as $£ 7.8 .6$ kon stuur nie.

Ten spyte van hierdie teenslae kon die werkskomitee ewewel op 18.9.1897 aan die Kommissie meedeel dat die betaalde bydraes ' $n$ bedrag van $£ 486: 10: 0$ verteenwoordig het, terwyl 'n verdere £364:16:0 toegesê was. Onder die eersgenoemde bedrag was ruim $£ 4$ van die distrik Carolina $£ 1: 10$ : van die distrik Piet Retief $£ 3$ van die wyk Hoëveld (distrik Heidelberg). 


\section{Die gedenkteken, Voorwaardes. Tenderpryse}

Reeds voordat die kommissie oor ' $n$ volledige oorsig van die fondse beskik het, is met J.N. Hekhuyzen, posbus 547, Pretoria, in verbinding getree om 'n tekening en die nodige spesifikasies van die beoogde gedenkteken te verkry. Aan hierdie versoek is op 31.8.1897 voldoen. Op dieselfde dag het Hekhuyzen hom bereid verklaar om 'n monument, vervaardig van sandsteen, vir $£ 450$ te lewer. Hierdie prys het nie die borsbeeld en 'n naamplaat van rooikoper en 'n tweetal metaalvase ingesluit nie. Na toewysing sou die monument binne drie maande gelewer kon word. Daar is reeds vroeër tenders gevra, terwyl die werkkomitee, bestaande uit Stiemens, dr Laxton en Keizer, gemagtig was om verdere reëlings te tref.

Op 6.9.1897 het Hekhuyzen gevra om die kommissievergadering te mag bywoon om sy tekening en voorstelle te kan toelig. Die kommissie was vermoedelik nie tevrede met die aanvanklike gedagtes oor die monument nie want op 20.9.1897 het Hekhuyzen vir die vervaardiging en oprigting van 'n granietmonument, volgens tekening $£ 700$ gevra terwyl ' $n$ monument van witmarmer 'en die rondgaande stoep met die vierpalen van die bÿgaandegraniet' vir £950 gemaak en opgerig kon word.

Die volgende dag het die kommissie verklaar dat Hekhuyzen se tender, vir 'n monument van blougraniet met ' $n$ sandsteenvoetstuk aanvaar is teen 'n koste van £650. 'n Gewysigde tekening (op skaal) en 'n nuwe spesifikasie moes ewenwel verstrek word voor die finale goedkeuring kon volg. Hekhuyzen het aan die voorwaardes voldoen en sowel die tekening as die granietmonster teruggekry. ' $n$ Maand later is stadsingenieur Lutz deur die kommissie gevra om sy benoeming as argitek van die monument goed te keur en op 30.10.1897 is die tender ( $£ 650$ ) aan Hekhuyzen toegewys. Die monument se hoogte sou 20 voet bedra, die fondering sou van harde klip en die monument van Belgiese graniet vervaardig word. Die graniet moes gedeeltelik gepoleer, geskuur en geprik word, daar sou 'n viertal pale met kettings met vierkantige skakels, om die voetstuk geplaas word, terwyl die beeltenis van It-kol Pretorius in rooikoper (brons) op die voetstuk aangebring sou word. Op die syvlakte van die voetstuk sou letters gekap en verguld word.
Dit is beklemtoon dat die boumateriaal egalig van kleur, hard en sonder gebreke moes wees en dat elke onderdeel van die monument in 'n afsonderlike kas verpak en vervoer moet word. Die monument moes agt maande na die ondertekening van die kontrak voltooi en opgerig wees. Omtrent die betaling is bepaal dat Hekhuyzen £400 na aankoms van die monument te Pretoria sou ontvang, terwyl die oorblywende $£ 250$ na plasing en goedkeuring van die gedenkteken aan hom uitbetaal sou word.

\section{Die oprigting van die monument voor die Staatsartilleriekaserne}

Onwillekeurig ontstaan die vraag wat die kommissie op die aanwending van ingevoerde, Belgiese graniet laat besluit het. Die beskikbare dokumentasie verstrek geen antwoord op hierdie vraag nie. Dieselfde geld vir die vervaardiging van die monument in Europa.

Op 12.11.1897 het Hekhuyzen die kommissie gevra om die plek vir die monument aan te wys omdat hy met die lê van die fondering wou begin. Ook wou hy graag weet wat die bewoording van die inskripsies, wat in Europa op die panele aangebring moet word, moet wees.

'n Langdurige tydperk van stilte het gevolg. Wanneer die N.Z.A.S.M. die kaste op die terrein afgelewer het, is onbekend, maar op 23.5.1898 het argitek W. Wÿsbek teenoor die kommissie verklaar dat hy, in opdrag van Hekhuyzen, aan J. Falochini opgedra het 'de buste of model van wÿlen Pretorius', soos goedgekeur deur Lutz, te vervaardig en om Falochini te kan betaal vir sy gelewerde dienste. Op dieselfde dag het Lutz aanbeveel dat Falochini £20 ontvang en dat dié bedrag van Hekhuyzen se tenderprys afgetrek word.

Die monument was omstreeks 27.7.1898 voltooi en op dié dag het die boukontrakteurs Daanen en Dorlas, van Pretoria, 'n volmag van Hekhuyzen aan voorsitter J.S. Smit gestuur waarin uitbetaling van die laaste bedrag (£250) aan hulle gevra is. Uit hierdie versoek, was op 28.7.1998 skriftelik deur Johannes Nicolaas Hekhuyzen herhaal is, kan afgelei word dat Hekhuyzen die genoemde bedrag aan Daanen en Dorlas geskuld het. Hekhuyzen is, soos dit uit 'n inspeksieverslag van Lutz, van 6.9.1898, aan die lig kom, vir die oprigting van die monument verantwoordelik gehou. Lutz het 'n grondige inspeksie verrig, bevind dat die monument nie water- 
pas was nie, dat die afwerking slordig en die vierhoekpilare bederf was en die kettings nie van smeedyster vervaardig was nie, maar van gietyster. Hy het aanbeveel om kontrakteur Hekhuyzen die £250 nie uit te betaal nie en dat die foute op sy koste deur ander herstel word. Op 5.12.1898 het Lutz 'n sertifikaat van betaling uitgereik. Argitek K. van Rÿsse het daarna die monument, op die 'voorplein' van die Artilleriekamp geïnspekteer. Volgens sy mening was die graniet (van Europa) sowel as die afwerking van die monument nie goed nie. Wel was dit geheel nou 'te lood', maw waterpas. Uit die beskikbare gegewens wil dit voorkom of Daanen en Dorlas die herstel en afrondingswerk van die monument verrig het.

Gebrek aan gegewens versluier waar en deur wie die monument vervaardig is. Dieselfde geld ook ten opsigte van Falochini wat o.a. 'n besondere hoogstaande kunswerk geskep het.

\section{Die grafmonument}

By wyse van 'n opmerking kan verklaar word dat die reeds genoemde Daanen en Dorlas verantwoordelik was vir die oprigting van It-kol. Pretorius se grafmonument en op 10.1.1899 die bedrag van $£ 250$, verminder met $£ 25$ van J.S. Smit ontvang het voordat argitek Klaas van Rÿsse op 27.1.1899 gesertifiseer het dat die monument in orde bevind is. Volgens Van Rÿsse kon die oorblywende bedrag nou uitbetaal word. Dieselfde argitek het die gehalte van die materiaal veroordeel maar daaraan toegevoeg dat hy niks daaraan kon doen nie omdat dit by aankoms deur die kommissie aanvaar was.

Die kommissie, wat aanvanklik van plan was om hom uitsluitend met die monument by die Artil- leriekaserne te bemoei, het - soos uit bostaande gegewens afgelei kan word - uiteindelik ook vir die oprigting en betaling van die monument op die begraafplaas gesorg en op dié wyse die 'Vader van die Staatsartillerie', It-kol. Henning Pretorius, aan die spreekwoordelike vergetelheid ontruk.

Vandag staan hierdie monument, 'n stil getuie van ons militêre verlede, voor die Verdedigingshoofkwartier, Potgieterstraat, Pretoria.

* Kol dr Jan Ploeger, is Staatshistorikus, verbonde aan die Staatsargief, Pretoria.

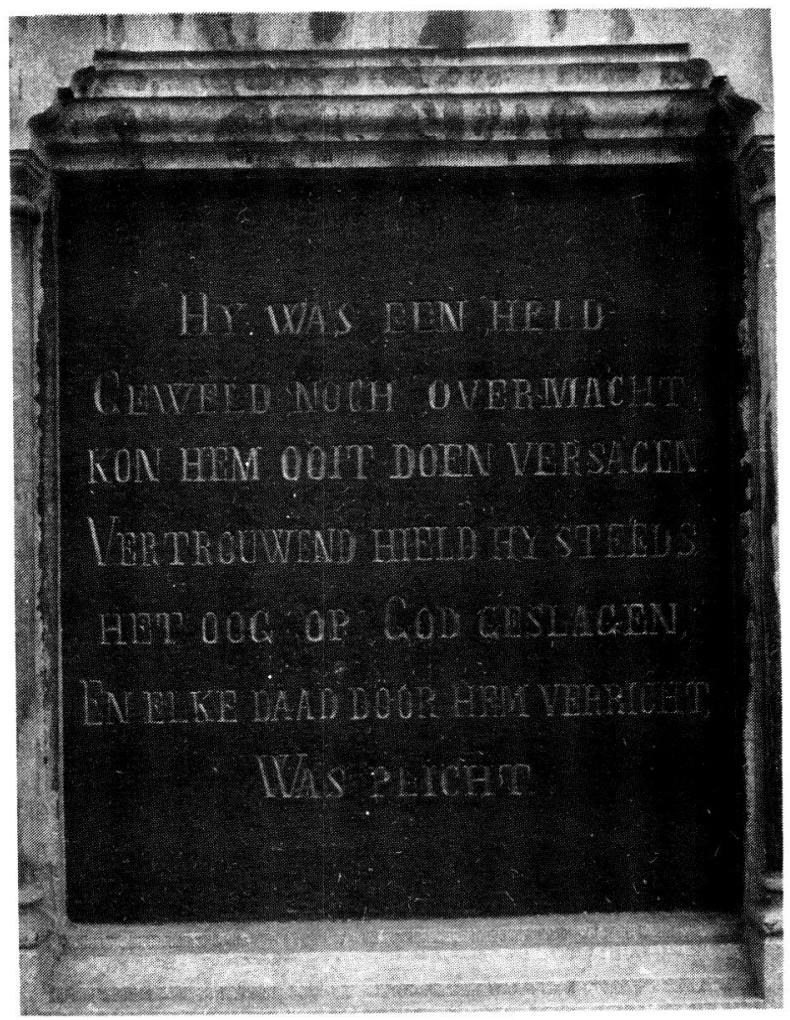

